\title{
The mast cell demystified: A novel target for anti-inflammatory strategies after circulatory arrest?
}

\author{
Leora B. Balsam, MD, ${ }^{a}$ and Abe DeAnda, Jr, $\mathrm{MD}^{\mathrm{b}}$
}

\footnotetext{
From the a Department of Cardiothoracic Surgery, New York University-Langone Medical Center, New York, NY; and ${ }^{\mathrm{b}}$ Division of Cardiothoracic Surgery, University of Texas Medical Branch at Galveston, Galveston, Tex. Disclosures: Authors have nothing to disclose with regard to commercial support.

Received for publication June 14, 2016; accepted for publication June 16, 2016; available ahead of print July 20 , 2016.

Address for reprints: Leora B. Balsam, MD, Department of Cardiothoracic Surgery, NYU-Langone Medical Center, 530 First Ave, Suite 9V, New York, NY 10016 (E-mail: leora.balsam@nyumc.org).

J Thorac Cardiovasc Surg 2017;153:77-8

$0022-5223 / \$ 36.00$

Copyright (c) 2016 by The American Association for Thoracic Surgery

http://dx.doi.org/10.1016/j.jtcvs.2016.06.026
}

Inflammation is a normal physiologic response to injury and stress that can become maladaptive under certain conditions. Although the inflammatory response is critical in wound healing and acts as the host's first defense against trauma, the same response (or amplified responses) may adversely affect the perioperative course of the cardiac surgery patient. There are a number of common maneuvers in cardiac surgery that trigger inflammatory cascades, including surgical trauma (skin incision and sternotomy), cardiopulmonary bypass (CPB), and ischemia-reperfusion of the heart after cardioplegic arrest. Whole-body ischemia-reperfusion, which occurs during procedures requiring hypothermic circulatory arrest (HCA), also results in tissue and organ injury secondary to oxidative stress and release of inflammatory mediators. Clinically, the exaggerated inflammatory response associated with CPB, cardioplegic arrest, and HCA (with reperfusion) results in loss of vasomotor tone and a form of distributive shock similar to sepsis. $^{1,2}$ This vasoplegic syndrome is notable for a decreased alpha-adrenergic microvascular response in skeletal muscle vascular beds, a propensity for coronary vasospasm, and increased vasoconstrictive responses in the lung and mesenteric microcirculations. Because the inflammation associated with cardiac surgery can be both adaptive and maladaptive, efforts to attenuate it should retain the benefits of the cascade without the detrimental side effects.

Identifying the best target for anti-inflammatory strategies remains a challenge, and broad-strokes approaches such as administration of corticosteroids and leukocyte filtration have not translated into improved clinical results. ${ }^{1,3}$ In this issue of the Journal, Kertai and colleagues $^{4}$ suggest an alternative target: the mast cell. Mast cells are recognized for their role in allergic reactions; however, they also are involved in nonallergic inflammatory responses. ${ }^{5}$ Located in perivascular spaces within tissues such as the heart, lung, skin, and mucous membranes, these cells produce a variety of cytokines, leukotrienes, and nitric oxide on stimulation. Activated mast cells also release the contents of their secretory granules, which include

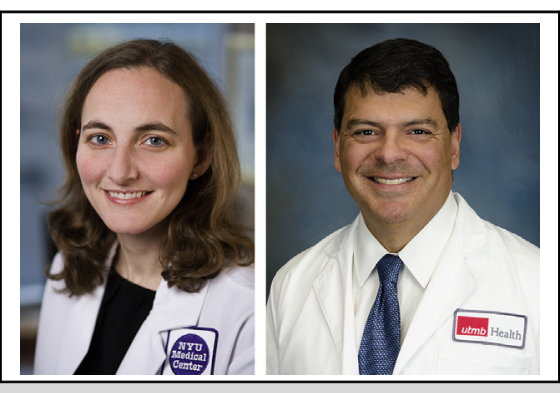

Leora B. Balsam, MD, and Abe DeAnda, Jr, MD

Central Message

Events during cardiac surgery, including periods of extracorporeal circulation, elicit a profound inflammatory response. The role of the mast cell in this process is underappreciated.

See Article page 68

histamine, kinins, and the proteases chymase and tryptase. Mast cells have been implicated in ischemia-reperfusion injury in numerous organ systems in experimental models, including the heart, ${ }^{6}$ spinal cord, ${ }^{7}$ and intestine. ${ }^{8}$ Kertai and colleagues ${ }^{4}$ hypothesize that mast cell activation is a key contributor to the vasoplegic response both during and after proximal aortic repair requiring $\mathrm{HCA}$.

The experimental basis for this hypothesis is prior work by Karhausen and colleagues ${ }^{8}$ in a rat model of deep hypothermic circulatory arrest (DHCA). In that study, adult rats were placed on $\mathrm{CPB}$, cooled to $16^{\circ} \mathrm{C}$ to $18^{\circ} \mathrm{C}$, and $\mathrm{DHCA}$ was instituted for 45 minutes. Animals were rewarmed, and specimens were harvested after 2 hours of recovery. The investigators found a link between intestinal injury after DHCA, intestinal mast cell activation, and systemic release of inflammatory cytokines. These effects were mitigated by pretreatment with the mast cell stabilizer cromolyn sodium. By extrapolating to the clinical realm, the authors propose that mast cell activation may be important in the vasoplegic response after HCA in humans.

In the current study, Kertai and colleagues ${ }^{4}$ measure levels of chymase and inflammatory cytokines in blood specimens of 31 patients undergoing nonemergency proximal aortic surgery with HCA. Blood specimens were collected at 4 time points: (1) induction of anesthesia ("baseline"); (2) nadir temperature before HCA ("target temp"); (3) 5 minutes after completing HCA ("post$\mathrm{HCA}^{\prime}$ ); and (4) termination of CPB ("post-CPB"). The 
authors note increased mast cell-specific chymase levels at all time points relative to baseline. When patients were dichotomized into those with low and high chymase responses, they also found a significant association between high chymase response and intraoperative hypotension. The authors speculate that inhibition of the mast cell response (eg, with a mast cell stabilizer) may protect against vasoplegia in this setting. Such inhibition would have to be timed early, and it should be emphasized that HCA is not the main effector in the cascade; the predominant increase in chymase levels occurred between baseline and the "target temp" measurements, presumably related to events that include incision, sternotomy, initiation of $\mathrm{CPB}$, and cardioplegic arrest. A useful follow-up to this study would include sample collection during each of these events, allowing one to better identify which elicits the bulk of the mast cell response.

One of the points highlighted by this study is that experimental models are inherently limited in their ability to predict the human clinical response. In their preclinical model, Karhausen and colleagues ${ }^{8}$ found that hypothermic $\mathrm{CPB}$ was not associated with an exaggerated mast cell response, but the addition of DHCA with reperfusion to hypothermic CPB was. This pattern of mast cell response is remarkably different than that described by Kertai and colleagues ${ }^{4}$ in this issue of the Journal. This may be a species-specific phenomenon or, alternatively, may relate to nuances of clinical management that are not replicated in the experimental model. Although intestinal mast cells are major players in the preclinical model, the early chymase response in the current study suggests that other sources (eg, resident cardiac mast cells) may be more important in clinical cardiac surgery. Kertai and colleagues ${ }^{4}$ logically conclude that the role of mast cell activation in cardiac surgery should be studied in other clinical models as well, including cardiac surgery without CPB and cardiac surgery without HCA.

Although this study ultimately answers fewer questions than it asks, it draws important focus on the mast cell as an underappreciated player in the vasoplegic response in cardiac surgery. The fact that mast cell activation can be pharmacologically suppressed makes this cell an attractive target for future therapies to mitigate the vasoplegic response.

\section{References}

1. Levy JH, Tanaka KA. Inflammatory response to cardiopulmonary bypass. Ann Thorac Surg. 2003;75:S715-20.

2. Ruel M, Khan TA, Voisine P, Bianchi C, Sellke FW. Vasomotor dysfunction after cardiac surgery. Eur J Cardiothorac Surg. 2004;26:1002-14.

3. Warren O, Alexious C, Massey R, Leff D, Purkayastha S, Kinross J, et al. The effects of various leukocyte filtration strategies in cardiac surgery. Eur J Cardiothorac Surg. 2007;31:665-76.

4. Kertai MD, Cheruku S, Qi W, Li Y-J, Hughes GC, Mathew JP, et al. Mast cell activation and arterial hypotension during proximal aortic repair requiring hypothermic circulatory arrest. J Thorac Cardiovasc Surg. 2017;153:68-76.

5. Theoharides TC, Kempuraj D, Tagen M, Conti P, Kalogeromitros D. Differential release of mast cell mediators and the pathogenesis of inflammation. Immunol Rev. 2007;217:65-78.

6. Oyamada S, Bianchi C, Takai S, Chu LM, Sellke FW. Chymase inhibition reduces infarction and matrix metalloproteinase- 9 activation and attenuates inflammation and fibrosis after acute myocardial ischemia/reperfusion. J Pharmacol Exper Ther. 2011;339:143-51.

7. Ma J, Zhang X-L, Wang C-Y, Lin Z, Tao J-R, Liu H-C. Dexmedetomidine alleviates the spinal cord ischemia-reperfusion injury through blocking mast cell degranulation. Int J Clin Exp Med. 2015;8:14741-9.

8. Karhausen J, Qing M, Gibson A, Moeser AJ, Griefingholt H, Hale LP, et al. Intestinal mast cells mediate gut injury and systemic inflammation in a rat model of deep hypothermic circulatory arrest. Crit Care Med. 2013;41:e200-10. 